\title{
Fatigue damage analysis of aluminized glass fiber composites
}

\author{
J.M. Ferreira ${ }^{\text {a,* }}$, J.T.B. Pires ${ }^{\text {b }}$, J.D. Costa ${ }^{\text {a }}$, Z.Y. Zhang ${ }^{\text {c }}$, \\ O.A. Errajhi ${ }^{\mathrm{c}}, \mathrm{M}$. Richardson ${ }^{\mathrm{c}}$ \\ a Department of Mechanical Engineering, University of Coimbra, 3030 Coimbra, Portugal \\ ${ }^{\mathrm{b}}$ Department of Industrial Engineering, ESTCB, IPCB, 6000-767 Castelo Branco, Portugal \\ ${ }^{c}$ Mechanical and Design Engineering Institute, Portsmouth University, Portsmouth, UK
}

Received in revised form 4 April 2005; accepted 12 July 2005

\begin{abstract}
Aluminized glass fiber composite with epoxy and polyester matrix were used in this work in order to study fatigue properties and its comparison to conventional glass fiber composites. Until now aluminized glass fiber materials have been only used as decoy flares in military applications. The innovative advantages of these composites, using modified fibers, are potentially the improvement of thermal and electrical conduction. The main objective of this work was to study the fatigue damage of coated fiber materials using stiffness loss and potential drop techniques. The failure mechanisms were analyzed using microscopy. Fiber contents and the resin effects in the fatigue strength were also tested and discussed.
\end{abstract}

(C) 2005 Elsevier B.V. All rights reserved.

Keywords: Aluminized glass fibers; Fatigue; Damage parameters

\section{Introduction}

The trend in studies of glass fiber composites in recent years has been towards developing materials with high physical and mechanical characteristics. Attention has also been concentrated on the creation of heat-resistant composites. Aluminized glass fiber composites present potential advantages, namely the improvement of thermal and electrical conduction, and impact and fatigue properties. Until now this innovative material has only been used in military applications. Therefore, its advantages must be experimentally confirmed by mechanical and physical properties characterization in order to make possible comparisons with the more common glass fiber composites and to explore possible civil applications.

Glass fibers currently used in composites production have relatively high-strength and high modulus. Some types of glass fibers have high heat resistance or particular dielectric characteristics. Epoxy resin are widely used in the production

\footnotetext{
* Corresponding author. Tel.: +351 239790700; fax: +351 239790701

E-mail address: martins.ferreira@dem.uc.pt (J.M. Ferreira).
}

of glass fiber composites due to their wetting power and adhesion to glass fiber, low setting shrinkage, considerable cohesion strength and adequate dielectric characteristics [1]. Glass fiber composites based on epoxy resin belong to the composites group for which maximum long-term strengths can be achieved. This fact determines their application in critical structures even at elevated temperatures. The endurance limit of epoxy-based composites is also very high. Some authors have demonstrated that a certain relationship exists between static and fatigue characteristics [2].

The main objective of this work was to study the fatigue behavior of an aluminized glass fiber composite with epoxy and polyester matrices. Polyester resin was also used in order to explore possible economical and surface appearance benefits. Some innovative advantages of these modified composites were anticipated, namely improvements in thermal and electrical conduction, hopefully without losses of static and fatigue properties. The electrical conductivity of some kind of fiber and/or optical fibers is widely used to "self monitor" fatigue damage [3-8] of composite laminates. This work report a experimental research to study the 
efficiency of self monitoring fatigue damage using electrical potential drop between the faces of the specimens in order to benefit of the electrical conduction of the aluminized glass fibers.

\section{Materials and experimental procedures}

This study involved two unidirectional hand lay-up composites manufactured in Advanced Composite Research Group, University of Portsmouth, using two selected termoset resins: Epoxy M36 film and an unsaturated polyester "Norpol 444-M 888" mixed with catalyst "methyl ethyl ketone peroxide 50\% solution in phthalate UN 2563" supplied by Reichhold UK Ltd. The release mould agent "Silside" supplied by Arrow Chemicals UK Ltd. was used throughout. The aluminized unidirectional E-glass fibers employed in this investigation were supplied by Chemring Group plc in 1-m length hanks, each hank having 100,000 fibers. The fibers were cut to the desired length. Laminates were fabricated in a mould of dimension $200 \mathrm{~mm} \times 150 \mathrm{~mm} \times 3 \mathrm{~mm}$. Fibers were placed carefully in the mould and initially consolidated after each layer using a roller. Three layers were used to produce a laminate approximately $3 \mathrm{~mm}$ thick. The complete assembly was placed in a hydraulic press machine with a
Table 1

Sheet series and cure parameters

\begin{tabular}{llll}
\hline Series & Resin type & $V_{\mathrm{f}}(\%)$ & Cure process \\
\hline $102-02$ & Epoxy & 54.2 & $3 \mathrm{~h}$ at $180^{\circ} \mathrm{C}$ followed $2 \mathrm{~h}$ at $130^{\circ} \mathrm{C}$ \\
$103-02$ & Epoxy & 54.2 & $3 \mathrm{~h}$ at $180^{\circ} \mathrm{C}$ followed $2 \mathrm{~h}$ at $130^{\circ} \mathrm{C}$ \\
$100-04$ & Polyester & 42.0 & $24 \mathrm{~h}$ at room temperature \\
$101-03$ & Polyester & 40.9 & $24 \mathrm{~h}$ at room temperature \\
$102-03$ & Polyester & 42.0 & $24 \mathrm{~h}$ at room temperature \\
$112-03$ & Polyester & 42.1 & $24 \mathrm{~h}$ at room temperature \\
$115-03$ & Polyester & 50.5 & $24 \mathrm{~h}$ at room temperature \\
\hline
\end{tabular}

pressure of $3 \mathrm{MPa}$ applied during $2 \mathrm{~h}$. After the samples were left to a cure process summarized in Table 1. The samples were removed and finally the panels were cut into specimens using a circular diamond blade saw. Volume fraction $\left(V_{\mathrm{f}}\right)$ was ranging from 0.40 to 0.54 . Series $100-04$ was manufactured using uncoated glass fibers.

To avoid the material degradation the properties of the boundary layer and the nature of the interaction between the matrix and the reinforced glass fibers must be controlled using chemically active compounds. In the case of the epoxy resins, a product called AGM- 9 was used to be an effective stabilizer of the glass fiber composites properties and prevent the fiber strength drops due to an effect caused by adsorbed moisture from the air and the development of micro cracks.

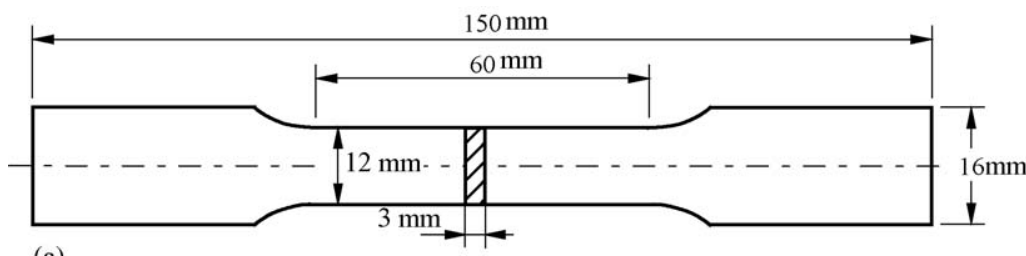

(a)

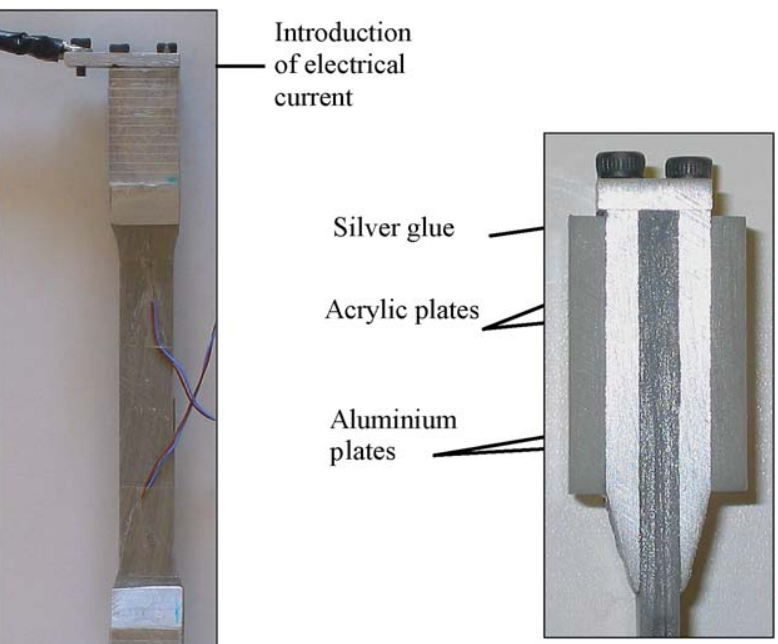

(b)

Fig. 1. (a) Specimen dimensions for fatigue and tensile tests. (b) Electrical monitoring. 
The electrical conductivity was determined using an impedance/phase analyzer of the Model Hp 419a, from which the electrical resistivity of the composite can be directly obtained.

The tensile properties were conducted using an electromechanical Instron Universal Testing machine. The fatigue tests were carried out on a servo-hydraulic Instron machine in constant amplitude loading.

All fatigue tests were performed in tension with a stress ratio of 0.05 and a frequency of $10 \mathrm{~Hz}$, at room temperature. The damage evolution was evaluated by measuring the loss in stiffness. The increase of electric potential drop with the number of cycles also was surveyed, proving itself as an alternative damage parameter $[6,9,10]$. The specimen geometry used in tensile and fatigue tests is shown in Fig. 1a. In order to minimize the electrical potential drop originated from the contact on the direct current introduction, fastening screws and silver gum were used as illustrated in Fig. 1b.

\section{Results and discussion}

Table 2 presents the average values and the standard deviation of three tests of each series. It includes the results of electrical resistivity in the fibers direction and the ultimate tensile strength of the seven series selected.

The aluminum coating caused a significant decrease in the electrical resistivity which presents significant variation related to the volumetric fraction of fiber in each series. In the fiber direction the resistivity was of the same order as metals, such as bronze, titanium, tungsten alloy and ductile iron [11]. This property will be used to monitorizing the fatigue damage in terms of the electrical potential drop between the two ends of the specimens.

The values of the longitudinal tensile strength depend of the volumetric fraction of fibers and the defects developed during fabrication. Usually it is observed that the tensile strength increase with fibers content [12]. A large scatter in tensile strength values were observed in series 103-02 caused by the high porosity levels of the composite as show in Fig. 2. The porosity content was controlled only by visual inspection and microscopy observations. An abrupt decrease of tensile

Table 2

Ultimate strength and electrical resistivity results

\begin{tabular}{lcl}
\hline Series & $\sigma_{\mathrm{Rm}}(\mathrm{MPa})$ & $\begin{array}{l}\text { Electrical resistivity on direction } \\
\text { of the fibers }\left(10^{-5} \Omega \mathrm{cm}\right)\end{array}$ \\
\hline $102-02$ & $118 \pm 11$ & 3.2 \\
$103-02$ & $74 \pm 37$ & 5.7 \\
$100-04$ & $444 \pm 6$ & $3.7 \times 10^{17}$ \\
$101-03$ & $100 \pm 11$ & 38.1 \\
$102-03$ & $96 \pm 9$ & 17.2 \\
$112-02$ & $99 \pm 16$ & 12.7 \\
$115-03$ & $107 \pm 4$ & 12.1 \\
\hline
\end{tabular}

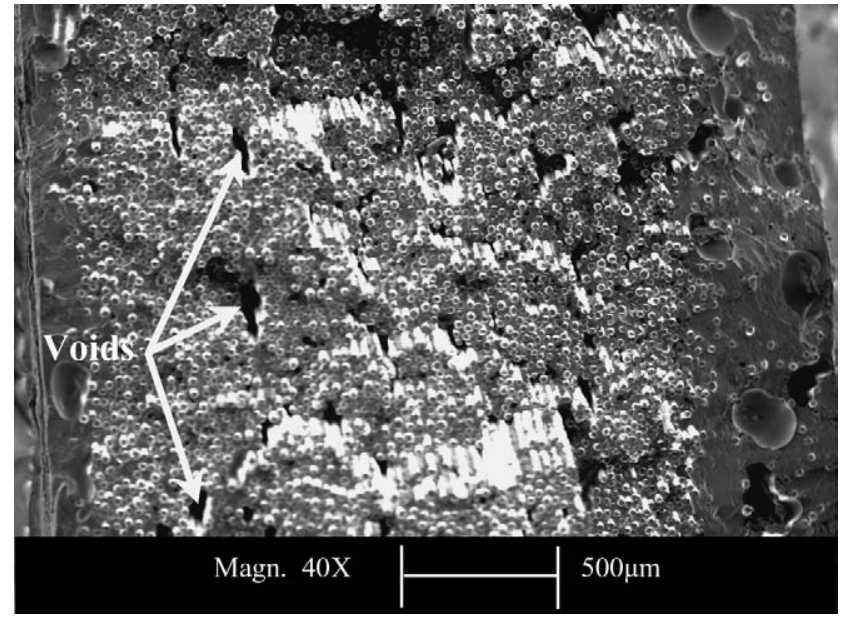

Fig. 2. Scanning electron microscopy image of porosities in transverse section (specimens series 103-02).

strength of the coated specimens (about 77\%) was observed when compared with uncoated fiber composite.

The fatigue tests were performed in order to obtain the fatigue strength of the polyester series with fiber volume fraction around $42 \%$. Also the fatigue tolerance was studied using as damage parameters the loss of stiffness and the electrical potential drop.
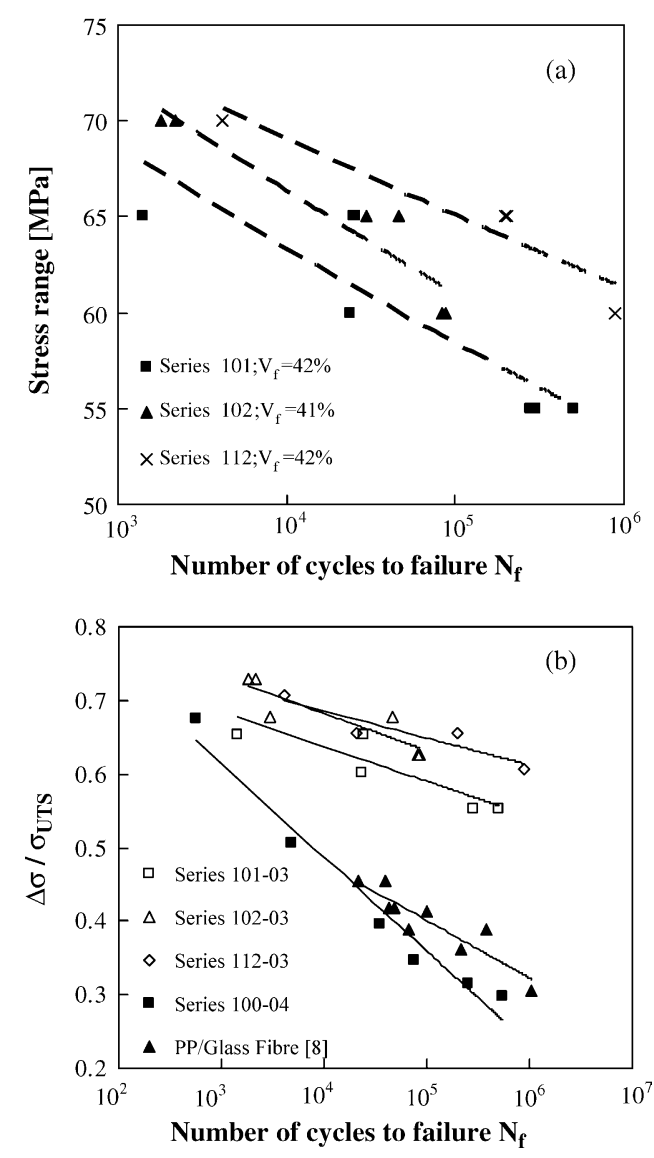

Fig. 3. Fatigue results: (a) stress range vs. $N_{\mathrm{f}}$; (b) $\Delta \sigma / \sigma_{\mathrm{UTS}}$ vs. $N_{\mathrm{f}}$. 

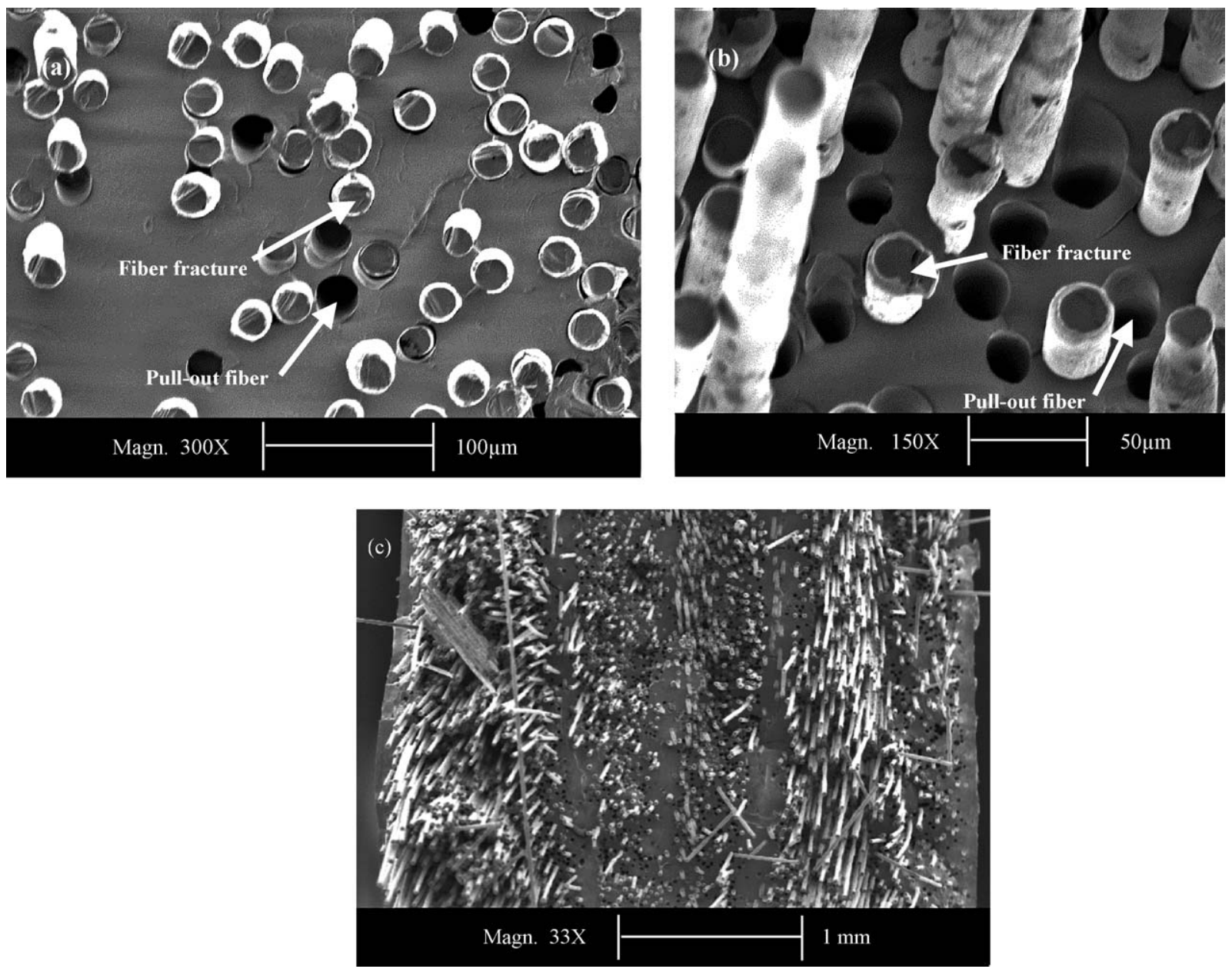

Fig. 4. Scanning electron microscope observations of the fatigue fracture surface. (a) Series 101-03. (b) Series 102-03. (c) Series 101-03.

Fig. 3a presents the fatigue results of the polyester composites in terms of stress range $\Delta \sigma$ versus fatigue life $N_{\mathrm{f}}$. The results show a similar trend for all the specimens presenting no significant scatter. Much lower fatigue strength is shown in the coated fiber composites than in the similar composites manufactured with uncoated fibers (Series 100-04). This significant decrease on fatigue strength of the coated composite may be caused by the weaker interface aluminum/polyester. In order to analyze the fatigue tolerance, these results were plotted in Fig. $3 b$ in terms of the non dimensional, $\Delta \sigma / \sigma_{\text {UTS }}$ parameter versus the number of cycles to failure, where $\Delta \sigma$ is the actual stress range and $\sigma_{\text {UTS }}$ is the ultimate tensile strength. In this figure the results obtained by Ferreira et al. for bidirectional balanced glass fiber, polypropylene composites, hand molded with seven layers manufactured from Vertotex "Twintex T PP" fibers with volume fraction of 0.338 [13], were superimposed. In spite of the relative low fatigue strength of the aluminized glass fiber composites observed in (Fig. 3a), as a consequence of its low tensile strength, these composites presents a very good fatigue tolerance and much higher than glass fiber/PP and polyester/glass fiber as shown in Fig. $3 b$.
Four failure mechanisms have been identified by observing the fracture surfaces in scanning electron microscope: the rupture of the matrix without destruction of the interface between matrix/fiber; separation of the interface between matrix/fiber; fiber rupture and pull-out the fracture fiber of the matrix as widely referenced in literature [14]. Abundant pullout fracture and fiber rupture can be seen in Fig. $4 a$ and $b$ for series 101-03 and 102-03, respectively. Fig. 4c also reveals a non uniform fiber distribution which may influence the low strength obtained for these materials.

In fatigue tests, the load and correspondent displacement of the specimens were periodically monitored during certain cycles. Two hundred points per cycle were recorded for each cycle from which the tensile stress versus strain was computed and plotted. These plots were nearly linear functions. The stiffness modulus, $E$, defined by the ratio between the tensile stress and the axial strain, was then derived from the stress-strain curves by linear regression. The stiffness modulus can be used as a fatigue damage parameter and in Fig. $5 \mathrm{a}$ and b. $E / E_{0}$ is plotted against $N / N_{\mathrm{f}}$, where $E_{0}$ is the initial value of $E, N$ the current number of cycles and $N_{\mathrm{f}}$ is the number of cycles to failure, for two tests series, 

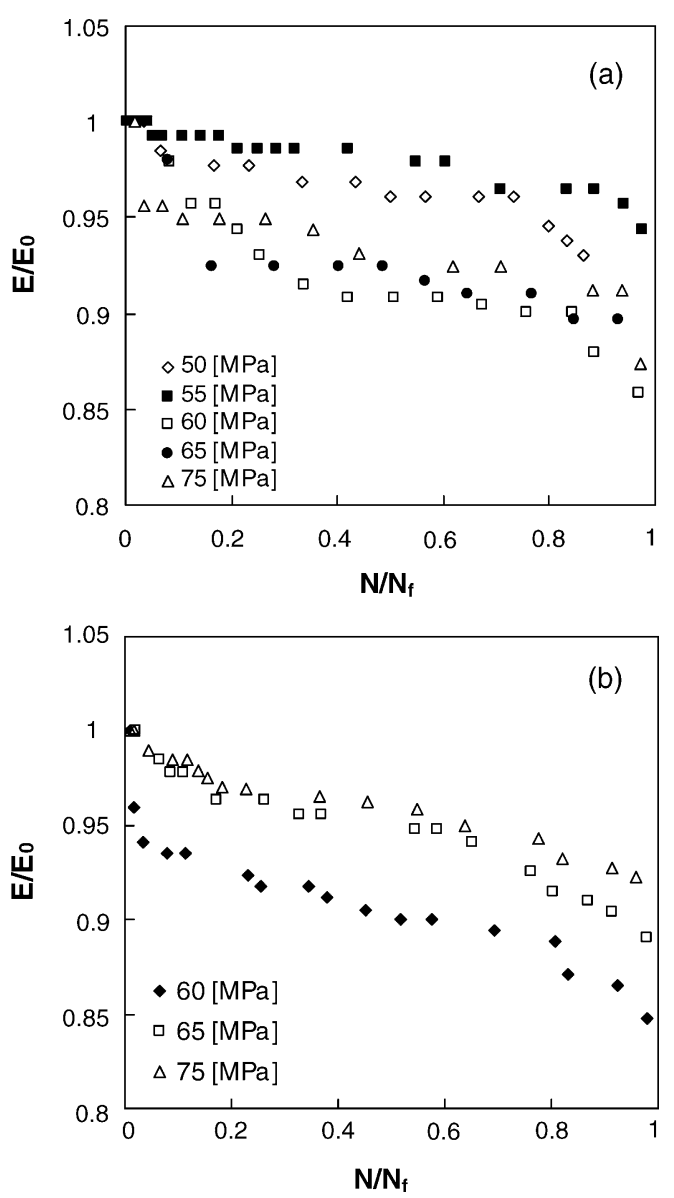

Fig. 5. $E / E_{0}$ against the normalized $N / N_{\mathrm{f}}$ number of cycles. (a) Series $101-$ 03. (b) Series 102-03.

101-03 and 102-03, respectively. The results show a trend similar with the typical behavior observed for the stiffness modulus in uncoated glass fiber/PP bidirectional balanced composites. A drop in stiffness modulus of about $5 \%$ was observed during the earlier cycles of the fatigue life, followed by a slow decrease until $90-95 \%$ of the fatigue life. Thereafter, another pronounced decrease in the stiffness modulus occurs until the final failure. Despite some scatter of the results, similar trends were observed for the majority of the tests.

In spite of the significant scatter observed, a behavior composed by three stages of stiffness variation were observed during fatigue tests, as illustrated in Fig. 5a and b, which is abundantly reported in literature for other composites materials. The first stage is the result of matrix cracking and fiber/matrix separation $[15,16]$. In the second stage $E / E_{0}$ reduction in a manner almost linear with the number of cycles, and results from damage propagation and the break of the first fibers [17-19]. Finally, in the third stage, an abruptly decrease of $E / E_{0}$ originates from the quick damage propagation, leading to the collapse of the composite [20]. The results do not present a well defined tendency with load which can be caused by heterogeneous fibers distri-
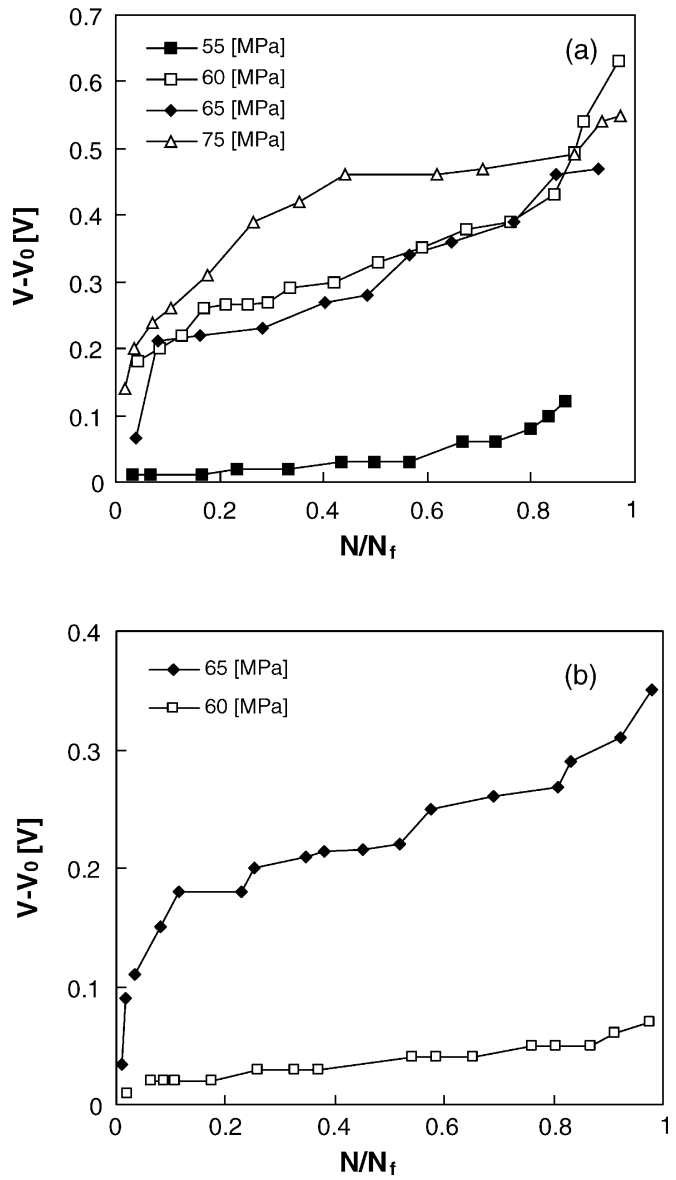

Fig. 6. Potential drop against the normalized number of cycles. (a) Series 101-03. (b) Series 102-03.

bution (as show in Figs. 2 and 4c) and the defective fibers alignment.

The potential drop between the specimen's ends was simultaneously monitorized (Fig. 1b) and recorded with load and displacement. The electrical potential drop is a measure of the damage caused by fiber breakages and the cracking of the matrix. An initial increase in potential drop is associated to some broken fibers, which were disordered in the fabrication process. Fig. $6 a$ and $b$ show the increase of the potential drop with the number of cycles for series 101-03 and 102-03, respectively.

Contrary to the uncoated glass fiber composites, the aluminized composites show a consistent and stable growth of potential drop as a consequence of their high electrical conductivity. This effect can be used as an alternative parameter for fatigue damage assessment. The relationship between the two alternative damage parameters, are illustrated in Fig. 7a and $\mathrm{b}$ for the series 101-03 and 102-03, respectively. In spite the great scatter observed the two parameters show a nearly linear relationship between them in the stable fatigue damage stage suggesting that the potential drop can be used to characterize the fatigue damage evolution of these materials. 

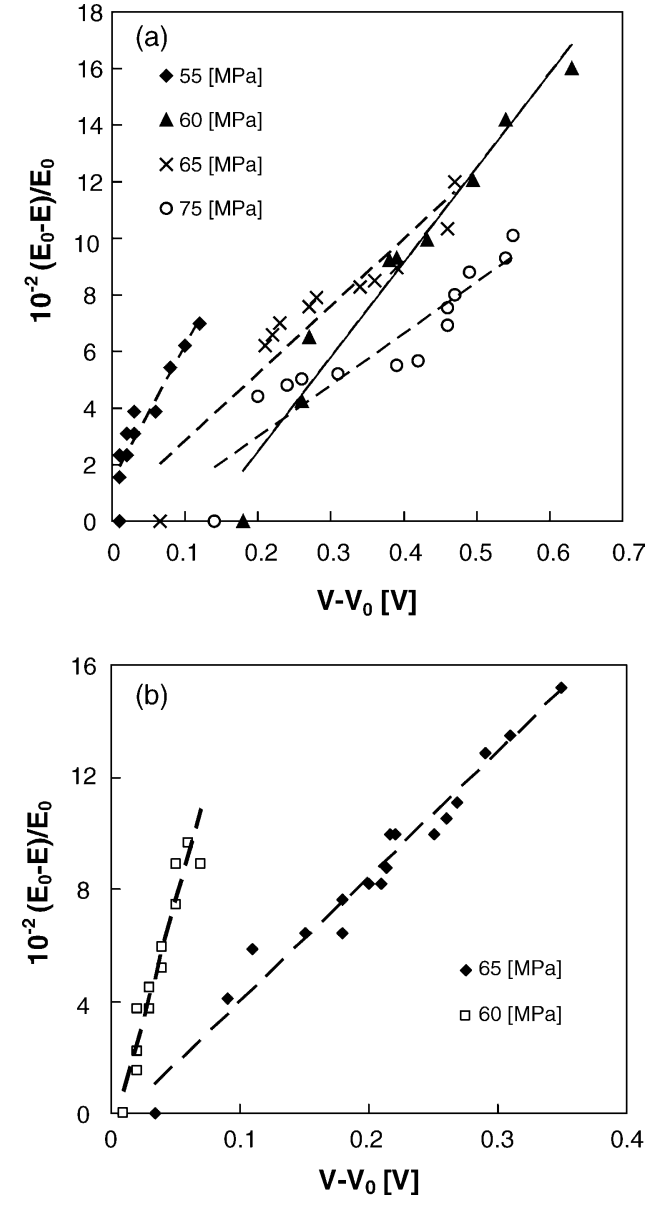

Fig. 7. $E / E_{0}$ against the potential drop values. (a) Series 101-03. (b) Series $102-03$.

\section{Conclusions}

(i) The tensile strength of aluminized composite is lower than uncoated composites. This is associated with the fabrication defects and the much lower strength of the aluminum interface when compared to uncoated glass fibers.

(ii) The potential drop values were enough accuracy to quantify fatigue damage, presenting a well defined increasing tendency with the number of cycles and with the fatigue stress level.

(iii) During the subcritical fatigue process potential drop presents an almost linear relationship with the loss of rigidity $\left(E / E_{0}\right)$.

\section{References}

[1] B.A. Rosemborgs, J. All-Union Chem. Soc. Named After D.I. Mendeleev 34 (1989) 453-459.

[2] P.P. Oldyrev, Mech. Comp. Mater. 2 (1981) 218-226.

[3] A.J. Rapoff, H.D. Dill, K.B. Sanger, in: Proceedings of 8th DOD/NASA/FAA Conference, Norfolk, VA, September 1990.

[4] Chr. Boller, R. Dilger, in: Proceedings of the AGARD Conference, Ohio, October 1992.

[5] K. Moriya, T. Endo, Trans. Jpn. Soc. Aero. Space Sci. 32 (1990) 184-196.

[6] C. Thiagarajan, P.E. Irving, in: Proceedings of the Aerotech, Birmingham, January 1994.

[7] N.J. Williamson, R.M.J. Kemp, P.T. Curtis, in: Proceedings of the 6th International Conference on Fiber Reinforced Composites, Newcastle 1994.

[8] Chr. Fischer, F.J. Arendts, Comp. Sci. Tech. 46 (1993) 319-323.

[9] K. Schulte, H.C. Baron, Comp. Sci. Tech. 36 (1989) 63-76.

[10] R. Prabhakaran, Exp. Tech. (1990) 16-20.

[11] ASM Handbook, vol. 1, Properties and Selection: Irons, Steels and High-Performance Alloys, ASM International, Materials Park, USA, 1995.

[12] C.M. Branco, J.A.M. Ferreira, M.O.W. Richardson, P. Fael, Int. J. Fatigue 14 (1992) 367-376.

[13] J.A.M. Ferreira, J.D.M. Costa, M.O.W. Richardson, Comp. Sci. Tech. 57 (1997) 1243-1248.

[14] B. Harris, Metal Sci. 14 (1980) 351-362.

[15] P.N.B. Reis, P. Fael, J.A.M. Ferreira, T.C. Devezas, in: Proceedings of the IV Congress Iberoamericano, de Ingenieria Mecanica, Santiago de Chile, Chile, 23-26 November 1999.

[16] S. Barré, M.L. Benzeggagh, Comp. Sci. Tech. 52 (1994) 369-376.

[17] K.L. Reifsnider, A.L. Highsmith, in: G.C. Sih, V.P. Tamuzs (Eds.), Fracture of Composite Materials, Martinus Nijhoff Publishers, The Hague, 1982, pp. 279-290.

[18] P.S. Steif, J. Comp. Mater. 17 (1984) 153-172.

[19] T. Gottesman, Z. Hashin, M.A. Brull, in: A.R. Bunsell, et al. (Eds.), Advances in Composite Materials, Pergamon Press, Oxford, 1980, pp. 749-758.

[20] K.L. Reifsneider, E.G. Henneke, W.W. Stinchcomb, J.C. Duke, in: Z. Hashin, C.T. Herakovich (Eds.), Mechanics of Composite Materials, Pergamom Press, New York, 1983, pp. 399-420. 